\title{
A controvérsia sobre a substituição de material didático impresso pelo tablet em um curso de EAD
}

\author{
Carolina Sousa do Nascimento Rabelo, \\ Centro Federal de Educação Técnica de Minas Gerais \\ Renato Caixeta da Silva \\ Centro Federal de Educação Técnica de Minas Gerais
}

\begin{abstract}
Resumo
Este trabalho objetiva analisar as razões que levaram os alunos de um curso de Letras a distância a recusarem o tablet e, consequentemente, a exigirem o retorno do material didático impresso. As respostas aos questionários foram analisadas sob uma perspectiva discursiva, com base na Linguística Sistêmico-Funcional.

Palavras-chave: material didático, formato tablet, Linguística SistêmicoFuncional.
\end{abstract}

\begin{abstract}
This paper aims to analyze the reasons for the students in an undergraduate degree distance course refusing to use the tablet and hence demanding the return of printed textbooks. The students' answers to the questionnaire were analyzed from a discourse perspective based on Systemic Functional Linguistics.

Keywords: study materials, tablet format, Systemic Functional Linguistics
\end{abstract}

\section{INTRODUÇÃO}

\section{Breve panorama sobre EAD no Brasil}

O ensino por correspondência postal foi o precursor da educação a distância (EAD) não apenas no Brasil, mas no mundo inteiro. A instalação das Escolas Internacionais, em 1904, fomentou a busca por cursos, especialmente nos setores de comércio e serviço na modalidade recém-criada (ALVES, 2009, p. 9).

O ensino por correspondência, com remessa de materiais didáticos pelos Correios, foi sucedido pelo ensino via rádio. Este possibilitou a educação popular por meio de seu sistema de difusão. Nessa seara, destaca-se o programa Mobral (Movimento Brasileiro de Alfabetização), que encontrou no aparelho de radiodifusão um grande meio de divulgação 
(ALVES, 2009, p.9).

A televisão para fins educativos começou a ser empregada a partir da década de 1960, tendo programas tanto em canais públicos quanto em canais privados. Entre as várias iniciativas bem sucedidas destacam-se os telecursos, que até hoje permitem que seus alunos obtenham a certificação pelo poder público (ALVES, 2009, p.10).

Os computadores associados à internet propiciam grandes avanços na educação a distância (EAD), posto que facilitam a transmissão e o acesso à informação. Ambos integram o atual cenário da educação a distância.

No Brasil, é livre o direito de ensinar e de aprender, eis que assim estatui o artigo 206, inciso II da Constituição Federal. Em sentido amplo, fundamenta-se aí o princípio da educação nacional e, por consequência, o da EAD (ALVES, p. 11).

A modalidade de ensino a distância intermediado pelo uso do computador adquiriu grande impulso no Brasil no século XXI. De acordo com o censo do Ministério da Educação, relativo a 2010, a educação a distância (EAD) possui 930 mil alunos de graduação. O crescimento do número de cursos de graduação a distância enseja diversos debates, entre eles, o relativo à importância e à adequação do material didático na mediação entre conteúdo curricular, tecnologias digitais e alunos.

Niskier (2009) é um entusiasta da tecnologia educacional. Para ele, a EAD somente tem a contribuir para a universalização da educação em um país com as mesmas proporções do Brasil. Esse pesquisador (2009, p. 30), ao criticar a resistência que existe no país ao uso da tecnologia educacional, cita um anúncio "Afinal, já não se fazem mais casas como antigamente. Nem avião. Nem rádio, nem jornal. Nem mesmo bola de futebol. A tecnologia muda tudo, e faz tudo melhor".

Romiszowski (2009, p. 403) corrobora o posicionamento de Niskier (2009), posto que, para esses estudiosos da EAD, o fator cultural é premente tanto na abertura quanto no fechamento a inovações tecnológicas. Segundo Romiszowski (2009, p. 403), "a realidade socioeducacional de hoje, com o crescente desenvolvimento de experiências online, indica uma ampliação da influência dos fatores culturais".

Mídias tradicionais como televisão, rádio, material impresso, mostraram resultados e ainda são importantes. Mas hoje é grande a influência das novas tecnologias, em todas as suas formas de informação e de sistemas baseados na integração de várias tecnologias. Apesar do quadro animador, ainda há pouco consenso em relação ao seu 
significado para o ensino-aprendizagem. Há entendimento insuficiente dos contextos, muita ênfase nos produtos e pouca em seus usos e impactos, principalmente em relação aos usuários (ROMISZOWSKI, 2009, p. 403-404).

Este artigo, por sua vez, não enfatiza o produto, no caso o tablet, pelo contrário, analisa os motivos que conduziram alunos a rejeitarem esse dispositivo, com base nas respostas que eles deram a um questionário que lhes foi aplicado. Utilizando os pressupostos da Linguística Sistêmico-Funcional (LSF), mais especificamente o sistema da avaliatividade, bem como considerando a importância dos fatores culturais na tomada de decisão dos alunos, os depoimentos desses sujeitos são analisados para se entender o que os levou a essa rejeição.

\section{Contextualização}

A inserção de aparatos tecnológicos tem se tornado não apenas uma necessidade, mas também uma exigência na sociedade moderna. Quando se trata de educação, essa demanda é ainda mais intensa, pois uma escola que não está a par das novas tecnologias da informação e da comunicação (TICs) corre sérios riscos de ser tachada de desatualizada. Esse risco é evitado pelas instituições de ensino superior (IES), principalmente aquelas que atuam no ramo da $\mathrm{EAD}$, por meio da adoção cada vez maior de aparatos tecnológicos mais modernos. É nesse contexto que a faculdade investigada julgou ser a mudança do material didático impresso pelo tablet a melhor decisão a ser tomada, com o propósito de atrair os alunos, supostamente ávidos por tecnologia.

No caso da faculdade investigada, diferentemente do que foi inicialmente pensado pelos mentores da estratégia de implantar o tablet como principal suporte para estudo, esse dispositivo móvel não foi bem recebido pelos discentes. Eles exigiram o retorno do material didático impresso. Foi essa postura dos alunos, surpreendente tanto aos olhos da IES quanto aos nossos, de tutora e de pesquisador, que nos levou à presente investigação. A questão inicial norteadora desta pesquisa foi: por que razão os alunos, estudantes de Letras a distância, presumivelmente acostumados a lidar com computadores, não se adaptaram e rejeitaram o tablet?

Nova e Alves (2003, p. 124) afirmam que a inserção de mídias audiovisuais e informáticas nos espaços escolares atende aos anseios do mercado de trabalho que praticamente obriga que a escola, seja de ensino superior, seja de ciclo fundamental, insira-se na ordem 
do mundo "tecnologizado". Elas ressaltam que essa incorporação, na maioria das vezes, ocorre de forma marginal, tendo em vista que, frequentemente, os aparelhos modernos são usados como material de apoio, como se fossem uma espécie de bônus ofertado pela instituição. Para elas, esse "bônus" seria um chamariz de "alunos-clientes que se sentem seduzidos pela presença das tecnologias no ambiente escolar”.

Nova e Alves (2003, p. 125) constatam que, para se entender mais a fundo a questão da educação e das tecnologias, é imprescindível refletir sobre o contexto pedagógico no qual surge a EAD. Para essas autoras, a educação a distância é uma tentativa "da educação formal de se apropriar das possibilidades de comunicação surgidas com a revolução digital, cujo locus de realização se concentra na Internet”. De acordo com essas autoras, o grande problema é o desprezo pela diversidade de ferramentas que os novos aparatos tecnológicos oferecem, uma vez que, no âmbito da $\mathrm{EAD}$, o que se verifica, frequentemente, é a mera transposição do modelo de educação presencial tradicional, preterindo, assim, o potencial criativo das tecnologias digitais.

Acrescenta-se a isso a ausência de discussões sobre as transformações na lógica da produção do conhecimento em virtude do advento da revolução digital, além da falta de reflexão sobre outros tipos de linguagens, que não seja a escrita apenas, para serem usadas no ambiente de EAD. As reflexões dessas autoras coadunam-se, de maneira inequívoca, com o que observamos dentro da sala de aula pesquisada neste trabalho.

Este artigo pretende, mesmo que superficialmente, fomentar a discussão acerca do uso de tablets em sala de aula. Até que ponto esse dispositivo pode ajudar os alunos no seu processo de aprendizagem? Ao longo de nossa pesquisa, percebemos que não basta colocar nas mãos dos discentes tablets ou aparelhos semelhantes, senão forem oferecidas capacitações para a utilização dos mesmos. No caso em foco, o principal problema foi a mera transposição do conteúdo impresso para o digital, sem se explorar os diferentes recursos que o ambiente virtual pode oferecer.

Essa constatação corrobora a problematização levantada por Nora e Alves (2003), no sentido em que, muitas vezes, as inovadoras ferramentas digitais são deixadas à margem, usando-se apenas o essencial da informática. Isso pode ensejar frustação dos estudantes, como a que aparentemente ocorreu na IES pesquisada, conforme será demonstrada ao longo deste artigo. 
Nesse ponto específico, é preciso fazer uma breve explanação sobre o contexto da faculdade investigada. Nela, os cursos de graduação possuem atividades tanto presenciais quanto a distância, tendo como principal mecanismo de transmissão de informações e de conteúdos um ambiente virtual de aprendizagem (AVA). Cada turma tem um encontro presencial por semana, no qual as aulas são transmitidas por satélite ao vivo.

Em linhas gerais, o livro didático é elaborado pelos próprios professores da instituição em debate, de acordo com a ementa da disciplina que lecionam. Cada módulo do curso tem seu respectivo livro com as matérias que lhe são afeitas, e contém explicações, textos diversos, exercícios e um espaço reservado para anotações dos alunos. Sendo assim, os livros, no que se refere à formatação e estética, são praticamente idênticos uns aos outros.

A ideia para a criação deste artigo surgiu a partir da observação de que alunos de uma turma de um curso de Letras semipresencial de uma faculdade particular, localizada em Belo Horizonte/MG, preferiram o livro didático impresso à versão digital acessível por meio de tablets. Essa rejeição do equipamento pelos discentes foi uma surpresa, posto que não se esperava que os alunos, estudantes de EAD, presumivelmente familiarizados com computadores, fossem preterir o tablet em prol do material didático impresso. Para investigarmos esse problema de pesquisa, optamos por aplicar questionários estruturados aos alunos, sendo as respostas analisadas sob o viés da Linguística Sistêmico-Funcional (LSF), mais especificamente do sistema da avaliatividade.

\section{EMBASAMENTO TEÓRICO: A TEORIA DE LINGUAGEM}

\section{A Linguística Sistêmico-Funcional}

O referencial teórico sobre o qual se alicerça este artigo é a Linguística SistêmicoFuncional (LSF), criada por Michael Halliday, que, segundo Almeida (2010, p. 11), é uma teoria de linguagem que dispõe de uma gramática capaz de descrever e de analisar as realizações linguísticas dos falantes/escritores, de forma sistemática e funcional, levando em conta fatores sociais e semióticos.

Para a teoria sistêmica, o significado é considerado uma escolha, pela qual a língua ou qualquer outro sistema semiótico é interpretado como uma rede de opções interligadas (HÁLLIDAY, 1994): o falante possui diversas opções, como se ele estivesse em um 
"sistema de rede", mas por alguma razão ele escolhe uma(s) em detrimento das outras.

O sistema de rede é uma teoria que entende a linguagem como uma fonte produtora de significados. Cada sistema dentro da rede representa uma escolha: não uma decisão consciente, feita em tempo real, mas uma variedade de possíveis alternativas, como 'assertiva/questão', ou 'singular/plural' [...]. O sistema inclui 1) a 'condição de entrada' (onde a escolha é feita), 2) o conjunto de opções possíveis, e 3) as 'realizações' (o que é para ser feito - ou seja, quais são as consequências estruturais de cada uma dessas opções) (tradução livre. HALLIDAY, 1994, p. 26).

Silva (2012, p. 33) citando Eggins (1994), aponta quatro pontos teóricos importantes sobre a linguagem, de acordo com a Linguística Sistêmico-Funcional, a saber: o uso da língua/linguagem é funcional; sua função primordial é produzir significados; esses são influenciados pelo contexto social e cultural de negociação; e o processo de uso da linguagem é semiótico.

A LSF enfoca o estudo da estrutura da língua a partir dos significados. Assim, a gramática concebida por Halliday propõe "uma divisão da linguagem em metafunções que resumem os três tipos de significados que podem ser realizados e que decorrem dos contextos - social e cultural - em que a interação ocorre" (BARBARA, 2009, p. 91). Essa teoria, embora faça parte da linguística, como seu próprio nome indica, diferentemente desta, não se restringe à análise da estrutura, da forma da língua isoladamente do uso ou do significado. Bárbara (2009, p. 91) esclarece:

\begin{abstract}
A LSF também se preocupa com a estrutura, uma vez que o estudo da estrutura da comunicação é necessário para se entender o significado das mensagens geradas na linguagem. Porém, de acordo com essa teoria, o significado é determinador da forma. Conforme as necessidades dos falantes em contextos específicos, são as escolhas no que tange às formas que expressam os significados desejados. Componentes fundamentais do significado na linguagem são, portanto, componentes funcionais (BÁRBARA, 2009, p.91).
\end{abstract}

Nesse sentido, as três metafunções (ideacional, interpessoal e textual) distinguemse pelas funções, ou significados, e determinados tipos de estrutura que cada uma possui. Quanto a esse aspecto, Silva (2012) faz as seguintes considerações:

A Linguística Sistêmico-Funcional considera a língua como um sistema no qual usuários fazem escolhas para a produção de significados (Neves, 2004), o que é uma ação social. A função primeira da linguagem é produzir significados, o que acontece a partir das escolhas dos usuários de uma língua ou outro sistema semiótico; e essas escolhas são influenciadas pelo contexto social imediato de uso da língua, e pelo contexto de cultura em que tais usuários estão inseridos (SILVA, 2012, p.30). 
Segundo Halliday (apud SILVA, 2012), os significados ideacionais correspondem à nomeação e à representação de objetos e ações; o significado interpessoal integra a relação e a interação entre os participantes; por fim, o significado textual reporta-se à estruturação juntamente com a organização textual da mensagem para torná-la compreensível.

Collins (2008) explica as três metafunções. A metafunção ideacional realiza-se pela transitividade, sendo, então, um sistema no âmbito da representação da experiência, da realidade. Já a transitividade é composta por três elementos principais: os participantes, os processos e as circunstâncias. A metafunção interpessoal enfoca a interação entre os participantes, a troca de significados entre eles. Collins, citando Halliday (1985), assevera que a metafunção interpessoal é o sistema que estabelece os papéis de fala, que são, basicamente, oferecer e pedir informações, bens e serviços. Por último, a metafunção textual refere-se à organização da mensagem no texto. O usuário da língua se expressa de modo que seu pensamento tenha lógica e coerência, dependendo de elementos coesivos, do contexto e de seu propósito.

\section{A avaliatividade}

Avaliatividade é um sistema de significação semântico-discursiva de caráter interpessoal. Refere-se à avaliação no discurso através do uso da linguagem. Em síntese, têm-se três principais elementos dentro do sistema de avaliatividade: atitude, gradação e fonte (engajamento). A atitude envolve afeto, julgamento e apreciação, nossas principais áreas de expressar avaliação. A gradação inclui força e foco, abarcando a escolha de aumentar ou diminuir a intensidade das atitudes, ou o avivamento, ou a atenuação de uma fronteira experiencial. Além disso, o engajamento acontece via uma única voz (monoglossia) ou via vozes de outrem (heteroglossia), que podem ser inseridas no discurso pela projeção, modalização e concessão (MARTIN \& ROSE, 2003, p.54).

Silva (2012, p. 59) assim sintetiza:

A atitude implica a avaliação através da expressão do afeto, do julgamento de caráter e conduta, e da apreciação de coisas materiais ou não. $O$ afeto implica expressão de emoção, sentimentos, pode ser positivo ou negativo, e ao mesmo tempo direto (através do uso de palavras que denotam o sentimento) ou indireto (através do uso de processos / comportamentos que indicam expressão da emoção). Pode acontecer também na expressão de uma qualidade (epíteto, atributo ou circunstância), um processo, ou um comentário. 
No tocante ao julgamento, Martin \& Rose (2003, p. 62) dividem-no em dois grandes grupos: estima social e sanção social. O primeiro envolve admiração e crítica, relaciona-se com normalidade (quão algo é incomum), capacidade (quão capaz é a pessoa), tenacidade (quão resoluto é a pessoa). O segundo tem a ver com a veracidade (quão confiável uma pessoa é) e com a propriedade (quão ético o indivíduo é). Nesse sentido, a distinção entre a estima social e a sanção social é imprescindível para se apurar as implicações na subjetividade e na objetividade da postura do avaliador.

Por fim, a apreciação valora as coisas, este termo entendido em sentido amplo, como objetos, instituições, relações, eventos, qualidades abstratas (SILVA, 2012, p. 60). Assim como o afeto e o julgamento, a apreciação possui dimensões positiva e negativa, correspondendo também a avaliações positiva e negativa de textos e de processos, compreende aspectos de composição, reação e valor das coisas.

Neste artigo, propõe-se fazer uma análise semântico-discursiva das respostas dos alunos aos questionários abertos a eles aplicados, embasada no sistema de avaliatividade, tendo como enfoque a atitude, considerando-se o afeto, o julgamento e a apreciação.

\section{Materiais didáticos em ensino a distância}

O ensino a distância, da maneira como se encontra atualmente, está intrinsecamente atrelado ao uso de Tecnologias da Informação e Comunicação (TICs). Nesse sentido, abre-se uma enorme gama de possibilidades de se explorar as diversas interfaces de aprendizagem possíveis, não apenas nos Ambientes Virtuais de Aprendizagem (AVA), mas também nos dispositivos móveis, como o tablet, que é o ponto central da investigação proposta neste artigo.

No caso da pesquisa aqui apresentada, a tipologia sugerida para o material didático em foco, conforme Fernandez (2009), seria livro-texto:

Livro-texto: é um recurso básico e fonte primária de grande parte de cursos EAD. Muitas vezes é denominado texto-base, o que significa ser complementado por outros textos. Esse material apresenta o conteúdo a ser estudado em determinada sequência, e é usado como referência teórica para a realização das atividades de um curso. É acompanhado de materiais auxiliares que apresentam informações complementares a determinado aspecto nele tratado ou que fornecem conteúdos necessários para sua compreensão. Pode ser acompanhado, também, por materiais que contêm ora as orientações sobre como e quando usá-lo (por exemplo, guias de estudo), ora um conjunto de exercícios que possibilitam a aplicação dos conteúdos estudados (por exemplo, caderno de exercícios) (FERNADEZ, 2009, p. 396). 
A temática abordada neste trabalho perpassa a questão do modo como são e como supostamente deveriam ser elaborados os materiais didáticos para cursos a distância, e também a questão da recepção desses materiais. Palange (2009) defende que, para se definir métodos de preparação de material para cursos online, é fundamental refletir sobre a estrutura da comunicação na esfera educacional. Essa autora expõe uma perspectiva interessante sobre a montagem de um curso virtual, a qual pode ocorrer de maneira monológica ou dialógica. De um lado, no caso do monólogo, opta-se pela transmissão da informação, nesse caso, o material é autoinstrucional e o aluno deve ser independente. Além disso, pode haver animações para ilustrar conceitos mais complexos, e com o acesso à internet, pode-se ter uma navegação hipertextual, que permitiria ao aluno ir além do texto que lhe é oferecido pelo material didático. De outro lado, no caso do diálogo, primeiramente, é preciso buscar informações sobre o aluno, justamente para que o diálogo seja exequível. Em acréscimo a isso, é essencial saber a finalidade, os objetivos e o contexto no qual se encontram os prováveis alunos do curso online, para que se elabore um material adequado às necessidades dos discentes. Palange (2009, p. 384) conclui que é fundamental "construir um espaço inicial anterior ao conteúdo do curso para que o aluno se familiarize com o ambiente, as ferramentas e os recursos disponíveis".

Quanto à recepção em si, este trabalho discute a inserção de recursos tecnológicos móveis em cursos de EAD, mais especificamente a troca de materiais impressos por dispositivos dessa natureza, e como essa ação é aceita ou não pelos alunos. A recepção desses dispositivos, como no caso aqui apresentado, pode nem sempre se dar de maneira tranquila, como aconteceu no contexto em que essa pesquisa ocorreu. Pouco tem-se estudado a respeito de recepção de materiais didáticos até então, e tal pesquisa pode lançar novos olhares sobre essa face do processo de uso de materiais didáticos, mais especificamente recursos de tecnologia móvel.

\section{METODOLOGIA}

Trata-se de um estudo de caso cuja abordagem é qualitativa. No caso dessa pesquisa, acreditamos que os questionários abertos eram a melhor opção, tendo em vista que nos possibilitariam ter acesso aos enunciados dos respondentes, ao contrário do que ocorreria 
se tivéssemos aplicado questionários fechados, os quais nos teriam oferecido apenas dados estatísticos, restringindo sobremaneira a possibilidade de utilização da teoria da LSF e do sistema da avaliatividade.

Consoante manifestações anteriormente expostas neste artigo, foi a rejeição do tablet pela maioria dos alunos de uma turma de EAD de um curso de Letras, exigindo, consequentemente, o retorno do material didático impresso, que norteou esta pesquisa. Nosso objetivo era descobrir por que razões, os discentes tomaram essa decisão. Assim, então, elaboramos o seguinte questionário:

\section{1) Qual sua relação com o livro didático?} $q u \hat{e}$ ?

2) Como você avalia a substituição do livro didático impresso pelo tablet? Por

3) Você acredita que teria dificuldade de aprender o conteúdo das disciplinas com o tablet?

4) Na sua percepção, quais são/foram as razões que te levaram a trocar o tablet pelo livro didático impresso?

5) Como você avalia o conteúdo que é disponibilizado no tablet? Por quê?

No processo de pesquisa, os questionários foram respondidos em formato impresso. Além disso, digitaram-se todos os dados coletados e estes foram inseridos em tabelas que foram divididas por questão em avaliação positiva e avaliação negativa.

Responderam ao questionário 11 (onze) alunos, sendo 7 (sete) mulheres, e 4 (quatro) homens, com faixa etária entre 25 e 42 anos. Eles foram chamados de A1, A2, A3 etc. As respostas foram analisadas sob uma perspectiva discursiva com base na LSF, empregando-se a avaliatividade, proposta por Martin \& Rose (2003). Verificaram-se as razões pelas quais os discentes ainda se encontram apegados ao suporte físico impresso (aqui também considerado livro didático), embora cursem graduação a distância.

\section{RESULTADOS}

Sobre a relação com o livro didático, tópico da primeira questão, verificou-se que, de 11 (onze) informantes, 09 (nove) expressam afeto e/ou apreciação positiva sobre sua relação com o livro didático. Ressalta-se que se sobressaem atitudes de afeto que identificamos como sentimento devotado ao livro, ao ato de ler e à posse do livro. 
O afeto expresso sob o sentimento devotado ao livro foi observado em A7: “[...] amo livro, sempre gostei de livro, de revista. Ler é tudo para mim. Fiquei muito triste (sic) isso foi tirado da maneira mais louca possível [...]" e em A8: "Ótima. Adoro nosso livro didático. Sempre fiz pesquisas em livro didático inclusive nos tempos de internet”.

O afeto referente ao ato de ler foi notado em A6: "A melhor possível. Gosto de ter o material em mãos para ler, reler a qualquer momento e lugar. Além disso, ele nos proporciona a possibilidade de grifar, escrever e selecionar informações relevantes." Também, em A10: "Minha relação com o livro didático é de estar sempre lendo, relendo, pesquisando e buscando informações.".

Por fim, o afeto relacionado à posse do livro é expresso em A1 e A4. A1: "Eu prefiro o livro didático ao tablet, pois gosto de anotar no livro, marcar etc." e A4: "Linda e feliz! Gosto de ter a liberdade de grifar partes importantes, fazer anotações. A leitura do livro é mais agradável."

A apreciação refere-se, basicamente, à importância (valor) atribuída ao livro, conforme visualizamos em A5 e A11. Em A5 "O livro é fundamental para qualquer estudante, e temos o livro mais perto e um contato maior com o conteúdo". Em A11 "Estreita. Recorro a ele com frequência e acho que as novas maneiras de apresentação de material didático não o substituem".

No tocante à segunda pergunta do questionário, a apreciação refere-se à diferença de modalidades (impresso $\mathrm{X}$ digital), ao funcionamento do dispositivo móvel, principalmente à sua eficácia, e também ao desconhecimento de como usar o tablet. Nesse sentido, os discentes que conhecem a tecnologia do tablet externaram apreciação positiva (A3 e A9). Já aqueles que não o conhecem, ou que se sentem inseguros quanto ao uso do tablet, expressaram apreciação negativa (A1, A2, A4, A5, A6, A7, A8, A10 e A11). Optamos por transcrever um exemplo de cada. A apreciação positiva é clara em A3: "Uma substituição muito acima do que eu esperava. $\mathrm{O}$ tablet me permite armazenar todo o material didático, não só o livro, sem que eu precise carregar um pesado fardo. A duração da bateria é excelente e, mesmo que o tablet estrague, ainda assim possuo todos os arquivos em outros dispositivos de armazenamento. Já se chovesse em meu material impresso... (sem contar que a natureza agradece)". Chamou-nos a atenção a apreciação negativa em A5: "Uma grande bobagem. O livro é para sempre e o tablet não é (sic) depende de senha e 
cada dia que passa fica desatualizado".

No que se refere à questão 3, a apreciação deu-se quanto à qualidade do tablet, A6: "Se o tablet fosse uma ferramenta ágil e que realmente funcionasse.", A7: "Sim, é lento, chato de mexer. Não responde bem aos comandos, é uma enganação"; e quanto à dificuldade de adaptação, A1: "Sim. Eu não me acostumei ainda, sou do tempo mais antigo. He, he... (sic)" e A2: “[...] a dificuldade com a informática também, é novo e ainda não me adaptei”. Percebe-se que alguns alunos atribuem alguma dificuldade em aprender com o dispositivo móvel devido a uma característica a ele atribuída, quando também reconhecem sua pouca familiaridade com ele.

Nas respostas à questão 4, sobre as razões para a troca, reparamos, mais uma vez, apreciação negativa quanto ao tablet e positiva quanto ao livro. A apreciação negativa é patente em A7: "Quando li a propaganda no site falava que ganhava o tablet, em momento algum falou que substituiria o livro por esta porcaria (sic). O livro é fundamental e foi-nos tirado". A2 manifestou julgamento e afeto: "Não, acredito que devemos estar abertos a novas experiências, porém me arrependi. Prefiro o livro impresso". As opiniões desses alunos levam-nos a crer que a qualidade tecnológica do tablet pode ter interferido na postura da turma relativa à adoção do mesmo.

Por último, no tópico 5, a apreciação positiva do tablet (A3, A4 e A9) relacionou-se à facilidade de pesquisa, ao passo que a apreciação negativa associou-se à dificuldades de operação, assim como às limitações técnicas do tablet (dependente de energia e de senha), como também acontece em algumas respostas à questão 4. Destaca-se que o conteúdo disponível no tablet era o mesmo que o do livro, conforme constataram A3, A4, A2, A8 e A11.

Conforme apresentado acima, observamos que a grande maioria dos alunos fez uma avaliação positiva quanto à relação que eles têm com o livro didático, especialmente quanto às possibilidades de manuseio que o livro oferece, expressas pelos verbos "grifar", "marcar", "anotar", e que, na percepção do público investigado, o tablet não supre. Mais um sinal da pouca familiaridade com o dispositivo eletrônico móvel.

Os dados sugerem que a maioria dos alunos avaliou negativamente a substituição do livro didático impresso pelo tablet aparentemente devido à qualidade inferior do dispositivo móvel e à dificuldade de se adaptar ao tablet. Recapitulando, houve mais afeto $\mathrm{e}$ apreciação 
positivos quanto ao livro didático, ao passo que houve mais afeto e apreciação negativos com relação ao tablet.

\section{REFLEXÕES FINAIS}

O material impresso está eminentemente relacionado aos primórdios da EAD, quando esta, em sua fase inicial, ocorria por correspondência (FERNANDEZ, 2009). Atualmente, mesmo com o advento das TICs, verifica-se que esse tipo de material ainda é largamente utilizado e, muitas vezes, vislumbra-se que, a despeito de algumas estratégias que priorizam a interação entre educandos e educadores, ainda prevalece a reprodução da situação presencial de ensino e de aprendizagem. Isso é visto pela transposição do material impresso do livro para o formato PDF, o que ocorreu na IES pesquisada.

Além disso, a simples inserção de aparato tecnológico moderno no ambiente escolar não é apta a produzir a capacitação tanto técnica quanto acadêmica dos alunos, posto que se trata de recursos didáticos auxiliares de uma prática escolar que permanece centrada na transmissão do saber escrito, portanto que não explora todas as possibilidades que as TICs podem oferecer. Aparentemente, foi isso que aconteceu no contexto pesquisado, pois não havia nenhuma diferença entre o conteúdo disponibilizado no material impresso e aquele acessível no tablet, visto que o arquivo apenas havia sido convertido para o formato PDF. Sendo assim, houve uma explícita subutilização das ferramentas que um tablet pode oferecer aos seus usuários.

A título de conclusão, é relevante a constatação de Nova e Alves (2003, p. 125) de que, na maioria dos cursos online, há a manutenção da lógica da educação tradicional, ensejando a mera transposição do modelo de educação presencial para a EAD, portanto, relegando o potencial criativo que as tecnologias digitais, o tablet, no caso deste estudo, oferecem a seus usuários. O mesmo parece acontecer em cursos semipresenciais como este em questão. O discurso dos discentes investigados mostra-nos que nem sempre eles estão preparados, seja tecnicamente, seja academicamente, para manusear dispositivos como o tablet. Sugerimos a verificação da qualidade do produto ou quaisquer outros aparelhos, pois se suas propriedades forem aquém do que é oferecido no mercado, em geral, isso pode ser fator de insatisfação dos alunos. Além disso, esta pesquisa pontuou que não basta apenas inserir o tablet em sala de aula, é necessário que haja planejamento, 
assim como preparação dos estudantes para usar TICs.

\section{REFERÊNCIAS BIBLIOGRÁFICAS}

ALVES, João Roberto Moreira. A história da EAD no Brasil. In: Educação a distância: o estado da arte. Frederic Michael Litto, Manuel Marcos Maciel Formiga (orgs). - São Paulo: Pearson Education do Brasil, 2009, p. 9-13.

BARBARA, Leila; MACEDO, Célia Maria Macedo. Linguística Sistêmico-Funcional para a análise de discurso: um panorama introdutório. In: Cadernos de Linguagem e $\begin{array}{lllll}\text { Sociedade } & 10 & (1), & 2009 . & \text { Disponível }\end{array}$ <http://www.red.unb.br/index.php/les/article/view/1212/871>. Acesso em 26 jul. 2013.

BRASIL. Presidência da República. Decreto $\mathbf{N}^{\mathbf{0}}$ 5.622, de 19 de dezembro de 2005. Disponível em: $\quad$ http://www.planalto.gov.br/ccivil_03/_Ato20042006/2005/decreto/D5622.htm>. Acesso em 02 jul. 2013.

COLLINS, Heloisa. Educação a distância e linguística aplicada sob a ótica da linguística sistêmico-funcional. In: Maria Otilia Guimarães Ninin \& Tânia Regina de Souza Romero (orgs). Linguística Sistêmico-Funcional como instrumento na educação. São Carlos: Pedro \& João Editores, 2008, p. 21-34.

FERNANDEZ, Consuelo Teresa. Os métodos de preparação de material impresso para EAD. In: Educação a distância: o estado da arte / Frederic Michael Litto, Manuel Marcos Maciel Formiga (orgs) - São Paulo: Perason Education do Brasil, 2009, p.395402.

HALLIDAY, M.A.K. An Introduction to functional grammar. New York: Edward Arnold, 1994, $2^{\mathrm{a}}$ ed.

LEILA, Bárbara. A teoria sistêmico-funcional e o ensino. In: NININ, Maria Otília Guimarães; ROMERO, Regina de Souza (orgs). Linguística Sistêmico-Funcional como instrumento na educação. São Carlos: Pedro \& João Editores, 2008, p. 103-108.

MAgalHaES, Célia M. A Análise Crítica do Discurso enquanto Teoria e Método de Estudo. In: Reflexões sobre a análise crítica do discurso/ Célia Maria Magalhães (org) Belo Horizonte: Faculdade de Letras, UFMG, 2001, p. 15-29.

MARTIN, J.R. Meaning Beyond the Clause: SFL Perspectives. Annual Review of Applied Linguistics: v. 22, USA: Cambridge University Press, 2002, pp. 52-74. Disponível em: <http://www.isfla.org/Systemics/Print/MartinPapers/JA-2002Meaning\%20beyond\%20clause\%20SFL\%20perspective.PDF>. Acesso em: 27 ago 2013.

MOTTA-ROTH, Désirée; HENDGES, Graciela H. Produção textual na universidade / Désirée Motta- 
Roth; Graciela Hendges Rabuske. São Paulo: Parábola Editorial, 2010.

NISKIER, Arnaldo. Os aspectos culturais e a EAD. In: Educação a distância: o estado da arte. Frederic Michael Litto, Manuel Marcos Maciel Formiga (orgs). - São Paulo: Pearson Education do Brasil, 2009, p. 29-33.

NOVA, Cristiane; ALVES, Lynn. Estação online: a "ciberescrita", as imagens e a EAD. In: Educação online/ Marco Silva (org) - São Paulo: Edições Loyola, 2003. p. 105134.

PRETI, Oreste. Avaliação da aprendizagem em cursos a distância: "delegando responsabilidades aos tutores?". In: SERRA, Antonio Roberto Coelho. Antonio Roberto Coelho Serra, João Augusto Ramos e Silva (Org.). Por uma educação sem distância: recortes da realidade brasileira. São Luis: EDUEMA, 2008, p. 237-247.

PALANGE, Ivete. Os métodos de preparação de material para cursos on-line. In: Educação a distância: o estado da arte / Frederic Michael Litto, Manuel Marcos Maciel Formiga (orgs), - São Paulo: Perason Education do Brasil, 2009, p. 379-385.

PERES, Rodrigo Sanches; SANTOS, Manoel Antônio dos. Considerações gerais e orientações práticas acerca do emprego de estudos de caso na pesquisa científica em psicologia. Interações. Vol. X. n. 20, p. 109-126. Jul-dez 2005.

ROMISZOWSKI, Hermelina das Graças Pastor. Fatores culturais na EAD: experiências de vários contextos. In: Educação a distância: o estado da arte. Frederic Michael Litto, Manuel Marcos Maciel Formiga (orgs). - São Paulo: Pearson Education do Brasil, 2009, P. 403-411.

SILVA, Renato Caixeta da. A Linguística Sistêmico-Funcional. In: Representações do livro didático de inglês: análise dos discursos de produtores e usuários com base na Linguística Sistêmico-Funcional / Renato Caixeta da Silva - 2012 - (tese).

\section{OS AUTORES}

Carolina Sousa do Nascimento Rabelo, mestranda em Estudos de Linguagens no CEFET/MG

E-mail: carolinasnascimento@gmail.com

Renato Caixeta da Silva, doutor em Estudos de Linguagens pela PUC/RJ, professor do CEFET/MG

E-mail: rencaixe@yahoo.com.br 